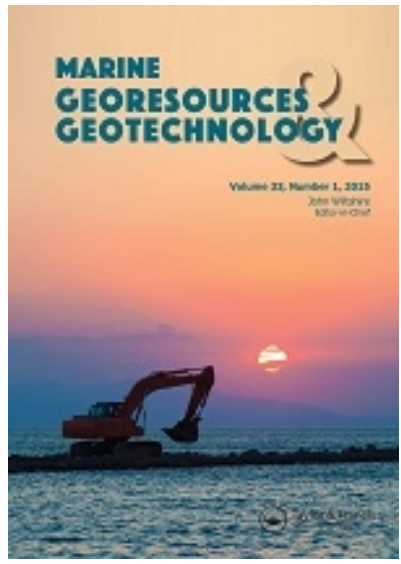

\title{
Finite elements method based on Galerkin's formulation for predicting the sand bars position
}

\begin{tabular}{|r|l|}
\hline Journal: & Marine Georesources \& Geotechnology \\
\hline Manuscript ID & Draft \\
\hline Manuscript Type: & Original Article \\
\hline Author: & n/a \\
\hline Complete List of Authors: & $\begin{array}{l}\text { López, Isabel; Universitat d'Alacant, } \\
\text { Pagán, José; Universitat d'Alacant } \\
\text { Navarro-González, Francisco; Universitat d'Alacant } \\
\text { Villacampa, Yolanda; Universitat d'Alacant } \\
\text { Hernández, Gabriela; Universidad Nacional del Centro de la Provincia de } \\
\text { Buenos Aires } \\
\text { Aragonés, Luis; Universitat d'Alacant }\end{array}$ \\
\hline Keywords: & $\begin{array}{l}\text { sandy beaches, sand bars, numerical modelling, precision profiles, } \\
\text { Galerkin }\end{array}$ \\
\hline
\end{tabular}

\section{SCHOLARONE Manuscripts}




\title{
Finite elements method based on Galerkin's formulation for predicting the sand bars
} position

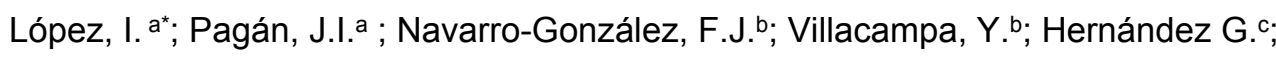 \\ Aragonés, L. ${ }^{a}$
}

aDept. of Civil Engineering, University of Alicante, Carretera San Vicent del Raspeig s/n, 03690 Alicante, Spain

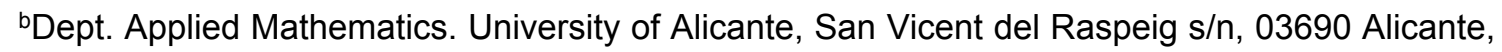
Spain.

'Facultad de Agronomía. Universidad Nacional del Centro de la Provincia de Buenos Aires (UNICEN). Azul, Buenos Aires, Argentina.

*Corresponding author: Isabel López. E-mail: isalopu.il@gmail.com

\section{Abstract}

The accurate knowledge of the location and movement of the sand bars is important for the coastal manager to establish correctly the coastal defence elements. This work applies a numerical model of finite elements based on Galerkin's formulation for predicting the location of the start, crest and end of the outer bar. The model that shows the best results is the one that combines the variables wave height, period and median sediment size. The mean errors are less than $10 \mathrm{~m}$ in the distance to the shoreline and $17 \mathrm{~cm}$ in the depth, while in the formulations proposed by other authors the errors are more than $100 \mathrm{~m}$ in the distance to the shoreline and $2 \mathrm{~m}$ in the depth. Thus, the proposed model significantly improves the calculation of the sand bars position. This will allow a better location of the coastal defence elements, and therefore an improvement in their effectiveness and optimisation of the materials to be used in their construction, key to sustainable coastal management. Furthermore, although the model was developed for the area of Valencia (Spain), the model can be used in any area with similar characteristics (open sandy beach), and the methodology (variables and process) could be applied worldwide.

Keywords: sandy beaches; sand bars; numerical modelling; precision profiles; Galerkin 


\section{Introduction}

Bars are an important morphological feature of sandy beaches, as they cause the transformation of the wave, and therefore the subsequent modification of the cross-shore beach profile (Holman and Sallenger, 1993). Generally, bars on natural beaches usually move toward the coast when wave energy is low, whereas they move quickly offshore when waves are energetic and the generated currents are strong (Ruessink et al., 2016; Winant et al., 1975). However, although there is huge amount of knowledge of sand bars there are still unknowns. Authors such as Dally and Dean (1984); Sallenger and Howd (1989), among others, have suggested that bar formation and migration are caused by the offshore waves direction, near the bottom, of seasonal flows of breaking waves ("hangover").

Several models have been developed to understand the evolution of the cross-shore beach profile (including the bars): i) the equilibrium profile models (Bruun, 1954; Dean, 1977); ii) descriptive models (Lippmann and Holman, 1990; Splinter et al., 2018); iii) models of empirical evolution of the profile (Kraus and Larson, 1988; Kriebel and Dean, 1985); and iv) process-based models (Bailard, 1982; Thornton et al., 1996). Energy-type models based on sediment transport (based on Bagnold (1966)) have often been used to predict morphological evolution, linking sediment transport to near-bottom flow. Thornton et al. (1996) used velocities measured near the bottom to propose an energy transport model. The model adequately predicted the sand bar offshore migration observed during high energy waves and strong medium flows, but not the movement of the bar toward shore and other small changes observed during low energy conditions. Gallagher et al. (1998) supported and extended the results of Thornton et al. (1996), including in the model the sediment fall velocity by varying it along the profile. This improves predictions of profile change. Again, the model successfully predicted seaward migration and bar erosion observed during storms. However, according to these authors, it was not possible to predict the migration towards the coast that was observed when the waves were moderately strong and the mean currents were weak. Although there are studies that show the migration of the sand bar onshore, as indicated in the following paragraph.

The difficulty of predicting the bar migration to the coast may be due to systematic changes in wave shape that occur over the bar. The waveform is often described as "skewed" or "asymmetric". (Elgar, 1987). Waves with positive asymmetry have high sharp peaks and wide, 
shallow trough. Elgar et al. (2001) observed that acceleration asymmetry tends to be maximum over the bar (where the break tends to be intense), and suggested that transport proportional to asymmetric acceleration could be responsible for the bar migration towards the coast. Hoefel and Elgar (2003) showed that the addition of wave freestream acceleration skewness leads to accurate predictions of bar migrations both to the coast and to the sea. Henderson et al. (2004) presented a model that combined the movement of water and sediment in the boundary layer, and that successfully predicted an event of migration from the bar towards the coast and an event towards the sea. But it failed to predict a second offshore migration event. Moreover, it is shown that, at the wave-resolving level, the onshore migration, largely due to the wave component of nearbed sediment transport (Falchetti et al., 2010; Hsu et al., 2006), can be properly represented if such sediment transport is described through the third-order moment of the nearbed velocity (Hsu et al., 2006). The recent work of Brocchini (2020) clarifies how the two perspectives (acceleration skewness for wave-averaging models and third-order moment of the nearbed velocity for wave-resolving models) can be reconciled through the freestream velocity asymmetry. Among the different models developed for bar prediction, the most commonly used variables are: wave height in deep water $\left(H_{o}\right)$, period $(T)$ or wavelength in deep water $\left(L_{o}\right)$, and median sediment size expressed explicitly $\left(D_{50}\right)$ or implicitly (fall velocity; w) (Demirci and Aköz, 2013; Gallagher et al., 1998; Kömürcü et al., 2007). Some of these authors also incorporate in their models the breaking wave height $\left(H_{b}\right)$ (Pape et al., 2007; Plant et al., 1999) and/or the slope $(m)$ (Plant et al., 1999; Różyński, 2003). It is worth mentioning the maximum wave height $\left(H_{\max }\right)$ used by Plant et al. (1999) or the direction of incidence of the waves with respect to the normal of the beach $(\theta)$ used by Pape et al. (2007). Most of these models also consider the duration of the wave during the test $(t)$.

The accuracy of the models is essential when locating coastal defence works. However, most of the models or numerical formulations obtained for the modelling of the bars have been developed in laboratory tests, where the wave height is generally regular and unique for the same test. This raises the question of what wave height should be used to represent the field observations. Therefore, the aims of this work are: i) determine the wave height (maximum height, mean height, height with a $0.137 \%$ probability of being exceeded) that best represents the characteristic points of the bars (crest, start and end); and ii) generate a numerical model that provides the position of 
89

90

91

92

93

94

95

96

97

98

99

100

101

102

103

104

105

106

107

108

these three characteristic points as precisely as possible, using the least number of variables necessary.

\section{Study area}

The study area is located to the North and South of the port of Valencia (Valencia, Spain). Nine transects have been analysed in this area, studying a length of $18 \mathrm{~km}$ of coastline (Figure 1). To the north of the port of Valencia, 4 transects have been established, divided as follows: i) one at Malvarrosa-Cabanyal beach (P1N); ii) two at Patacona beach (P2N and P3N); and iii) one at PortSaplaya beach (P4N). In the southern zone the distribution of the 5 transects is: i) two at Pinedo beach (P1S and P2S); ii) two at Saler beach (P3S and P4S); and iii) one at La Dehesa beach (P5S).

The study area is a very dynamic zone that has undergone numerous morphological changes in the studied period (November 1992 to April 2014). In the middle of 2008 the Valencia port underwent an extension of the northern breakwater which was completed in 2010. This caused a greater sheltering of the waves both to the beaches of the North and to those of the South which led to a greater longshore transport towards the south, which implied a significant accretion on the northern beaches, and less obvious erosion on the southern beaches (Aragonés et al., 2019b). The area has also undergone various beach nourishments such as the Pinedo beach in 1999 or the Cabañal-Malvarrosa beach in the period 2004-2006.

Finally, it should be noted that it is a microtidal zone, where astronomical tides $(20-30 \mathrm{~cm})$ together with meteorological tides can reach $75 \mathrm{~cm}$ (Ecolevante, 2006). 
109

110

111

112

113

114

115

116

117
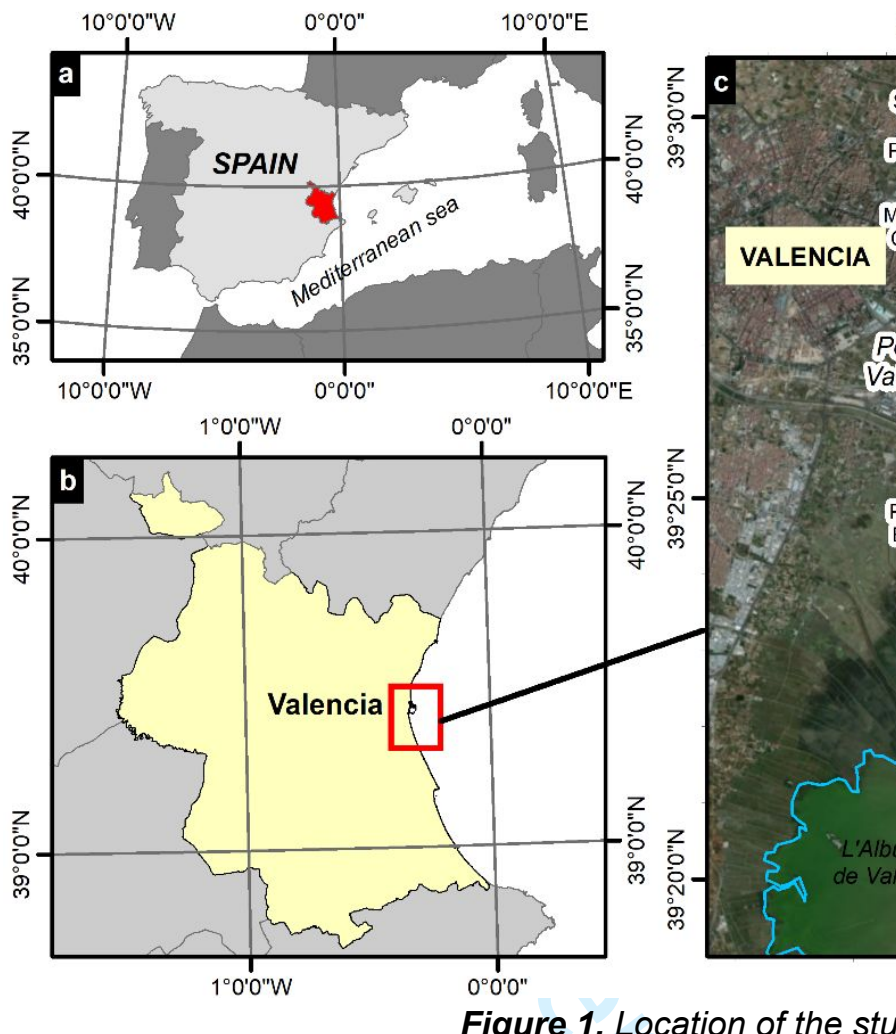

$0^{\circ} 20^{\prime} \mathrm{O}^{\prime \prime} \mathrm{V}$
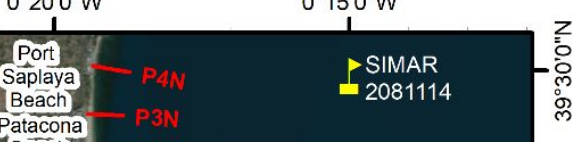

VALENCIA Cābanyal

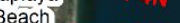

Beach

P2N

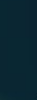

Mediterranean

Sea

Figure 1. Location of the study area.

\section{Methodology}

The following sections indicate the procedure used for data collection and the generation of the different models.

\subsection{Data collection}

Below is a description of the process used to obtain the variables necessary for the subsequent generation of models, such as: position of the bars, waves and sedimentology.

\subsubsection{Position of the bars}

The position of the bars was analyzed by determining the distance from the shoreline $(X)$ and the depth $(\mathrm{Y})$ of the points of start (s), crest (c) and end (e) of the bar (Figure 2). In those profiles where no bar was found, the distance from each point to the shoreline has been obtained as the average of the position of the previous and posterior profiles, and the corresponding depth in the profile at that distance (López et al., 2017). 
125

126

127

128

129

130

131

132

133

134

135

136

137

138

139

140

141

142

143

144

145

146

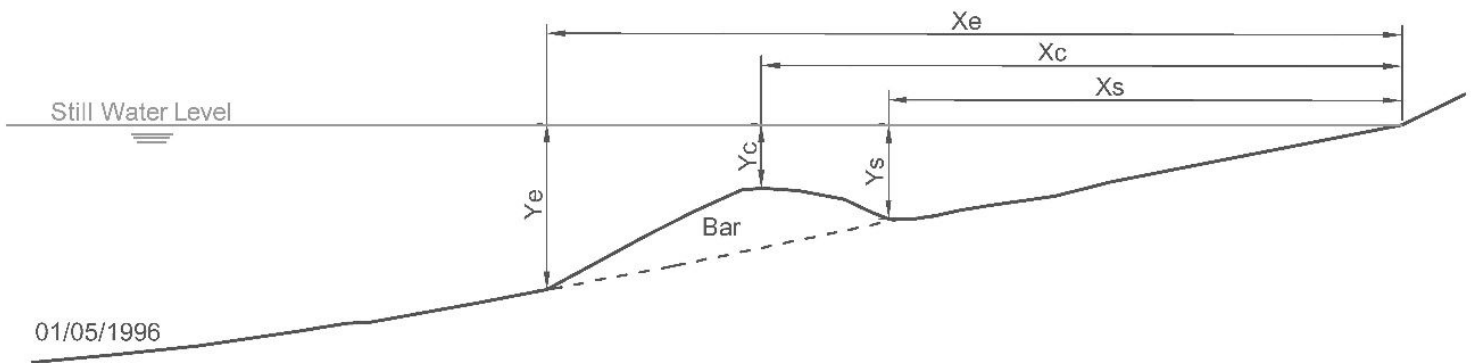

Figure 2. Location of the three characteristic points of the bar.

A total of 209 bimonthly collected profiles were analysed, distributed over time as can be seen in the Supplementary data 1: Distribution and use of profiles. The choice of months for sampling was conducted so that representative information was always obtained from the summer (profile after the season of calm swells) and winter profiles (profile after the storm season). The Profiling Bar method (BP) was used to obtain the profiles (Serra Peris and Medina, 1996). Following a methodology similar to terrestrial topography, this method makes it possible to determine the height of the beach profile with an error of less than $2 \mathrm{~cm}$, independently of the mean sea level by astronomical tide and its oscillation by waves.

To establish the position of the bars, the software developed by Pagán et al. (2017) was used to load and plot beach profile data. By means of a displacement control the user can obtain, for any entered distance, the elevation in each point of the profile. The start position, the crest, the end and the width of the sandbar are saved, up to a maximum of three sandbars per profile. The accuracy of the results will depend on the precision of the profile survey. Since in this research high-precision beach profile surveys were used, the identification of the sandbars was precise.

Afterwards, an analysis was carried out to determine the outliers to identify possible measurement errors. Those profiles that were considered as outliers in some of the study points were eliminated from the subsequent study (Figure 3). Specifically in this study 7 profiles were eliminated: 3 by outliers in the Xs; 1 by outlier in the Yc; 1 by outlier in the Xc and Yc; 1 by outlier in the Xs, Xc and $\mathrm{Xe}$; and 1 by outlier in Ye. 

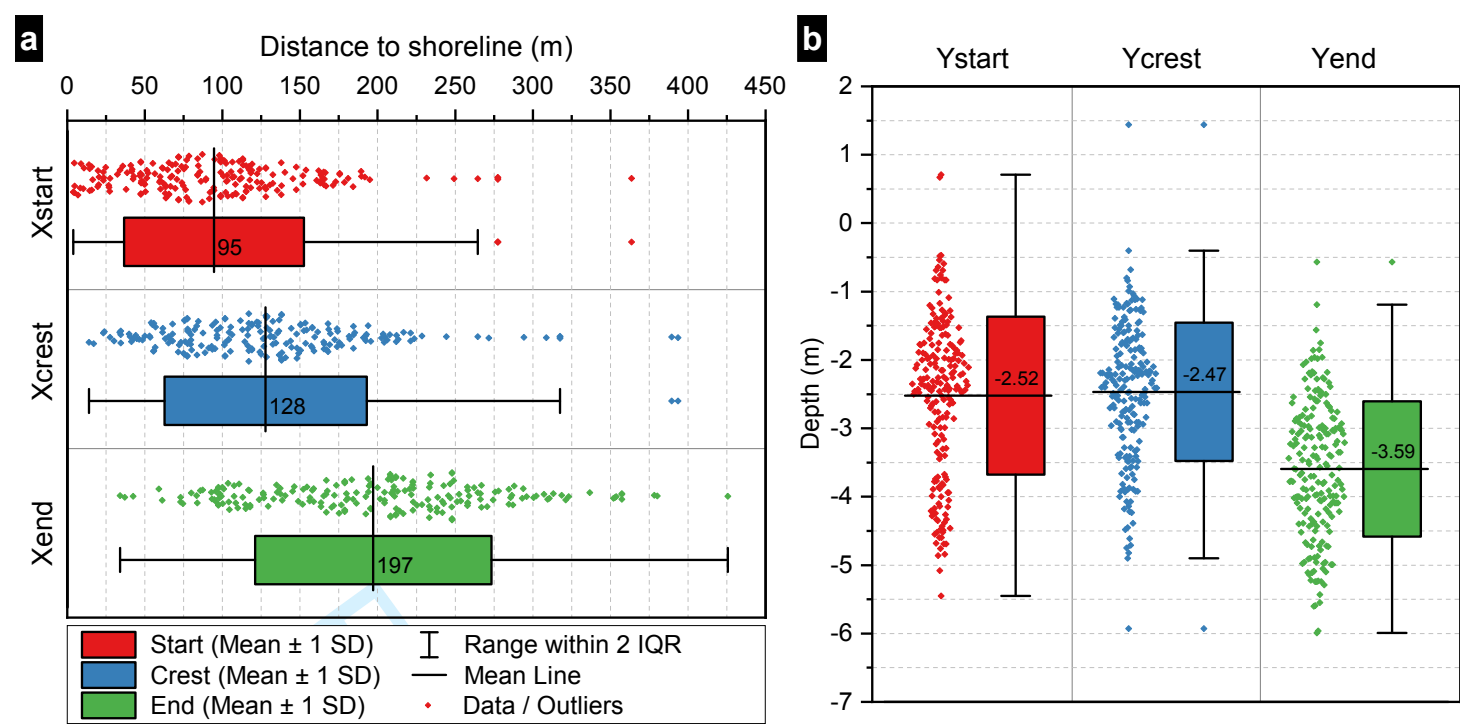

Figure 3. Outliers detected in each one of the study points of the bars.

\subsubsection{Maritime climate}

Data on wave height, period and wave direction were obtained using data from the SIMAR nodes provided by the Public Organization Puertos del Estado (www.puertos.es/enus/oceanografia/Pages/portus.aspx). These data, recorded every 3 hours since 1958, are based on high-resolution numerical modelling of the atmosphere, sea level and waves of the entire Spanish coastline. Specifically, data from SIMAR node 2081114 was used for transects in the North zone, and SIMAR node 2081113 for transects in the South zone. For each of the profiles the AMEVA software (IHCantabria, 2013) was used to obtain the wave height $H_{s, 12}$ (wave height with a probability of $0.137 \%$ of being exceeded in the studied period), the mean wave height $\left(H_{m}\right)$, and the maximum wave height $\left(H_{\max }\right)$ produced between the survey of each profile, as well as their corresponding periods $(T)$ and directions $(\theta)$. The breaking wave height $\left(H_{b}\right)$ was also obtained using the formula proposed by Komar and Gaughan (1972) (Equation 1). The use of wave height with probability $0.137 \%$ is due to its involvement in sediment transport (Hallermeier, 1978).

$$
H_{b}=H_{o} \cdot 0.56\left(H_{o} / L_{o}\right)^{-1 / 5}
$$

Where $H_{o}$ is the wave height in deep water (in this case the $H_{\max }, H_{m}$ and $H_{s, 12}$ ), $T$ is the period associated with this wave height, and $L_{o}$ is the wavelength in deep water obtained as: $L_{o}=\mathrm{g} \cdot T^{2} / 2 \pi$ 
168

The wave height is obtained in each of the profiles taking into account only the influential wave. In this way, the influence of the enlargement of the port is considered.

\subsubsection{Sedimentology}

The sedimentology was obtained from the dry beach samples collected during the sampling campaign carried out by the University of Alicante in 2013. For the characterisation of the sedimentology in each of the profiles, the median sediment size $\left(D_{50}\right)$ of the sample closest to the transect was used. In the study area, the median sediment size is between 0.167 and $0.332 \mathrm{~mm}$.

\subsection{Modellization}

The first step in modelling the characteristic points of the bars was to determine the variables to be used. For this purpose, the existing models were studied, analysing the variables used by the different authors (Table 1). The most commonly used variables are wave height and period, or some derived from them such as wavelength. In addition, among the studied models, $58.3 \%$ use the profile slope and $33.3 \%$ use the median sediment size.

However, the majority of the authors, given that they carry out their studies in flume channel, does not specify the wave height that would correspond to the reality. For this reason, firstly a correlation study is executed to determine which variables most influence the position of the points of the bars. Using the SPSS software, a study of correlations between inputs $\left(H_{\max }, H_{b, \max }, T_{\max }\right.$, etc) and outputs (Xs, Ys, Xc, Yc, Xe and Ye) was carried out. This study indicated that the greatest correlations occur with the slope, and in some cases with the median sediment size, but for variables related to wave height the correlations were very low in general, and none of them were outstanding among the rest.

Table 1. Variables used by other authors.

\begin{tabular}{|l|l|l|l|l|l|l|}
\hline & $\mathbf{D}_{\mathbf{5 0}}$ & Slope & \multicolumn{1}{|c|}{ Wave height } & Period & $\begin{array}{c}\text { Wave } \\
\text { direction }\end{array}$ & \multicolumn{1}{|c|}{ Others } \\
\hline Horikawa et al. (1973) & No & No & Yes, unspecified & Yes & No & Test duration \\
\hline Hallermeier (1978) & No & No & Yes, $\mathrm{H}_{\mathrm{s}, 12}$ & Yes & No & \\
\hline Larson and Kraus (1989) & No & No & Yes, breaking & No & No & \\
\hline Silvester and Hsu (1997) & No & Yes & Yes, unspecified & Yes & No & \\
\hline Hsu (1998) & No & Yes & Yes, unspecified & Yes & Yes & \\
\hline $\begin{array}{l}\text { Günaydın and Kabdaşlı } \\
(2005)\end{array}$ & No & Yes & Yes, unspecified & Yes & No & \\
\hline Kömürcü et al. (2007) & Yes & Yes & Yes, unspecified & Yes & No & \\
\hline Demirci and Aköz (2013) & Yes & Yes & Yes, unspecified & Yes & No & \\
\hline Gallagher et al. (1998) & Yes & No & Yes, $\mathrm{H}_{\mathrm{s}, 12}$ & No & No & \\
\hline Pape et al. (2007) & No & No & Yes, $\mathrm{H}_{\mathrm{rms}}$ and $\mathrm{H}_{\mathrm{b}}$ & Yes & Yes & \\
\hline Plant et al. (1999) & No & Yes & Yes, $\mathrm{H}_{\max }$ and $\mathrm{H}_{\mathrm{b}}$ & Yes & No & \\
\hline Różyński (2003) & Yes & Yes & Yes, $\mathrm{H}_{\mathrm{s}, 12}$ & Yes & No & \\
\hline
\end{tabular}


Second, multiple linear regression models were generated using the backward method, which consists of introducing all possible variables and the SPSS software generates linear models by eliminating the variables one by one. Thus, once the models had been made for each of the outputs, it was observed that the slope and the median sediment size remained in practically all the linear models generated. By contrast, the remaining variables were distributed randomly, leaving in some models the maximum height, or mean height, or $H_{s, 12}$, or a combination of them. In addition, the generated models did not explain more than $50 \%$ of the total sample and did not solve the problem of choosing between one wave height or another. Therefore, there is no linear relationship between dependent and independent variables, so it was decided to use non-linear models, specifically numerical models of finite elements.

There are several numerical modelling methodologies that have been applied in the study of engineering problems. In the last decade, numerical methodologies have been developed based on the generation of geometric models of finite elements in a hypercube (Navarro-González and Villacampa, 2013; Navarro-González and Villacampa, 2012; Villacampa et al., 2009). Recently, a new numerical methodology has been developed that applies in a hybrid way the Galerkin method and the finite element method (Navarro-González and Villacampa, 2016), which has been successfully applied in coastal engineering to model the depth of closure (Aragonés et al., 2019a). This methodology will be applied in this research to generate numerical models, since Galerkin's formulation of the finite element method (Navarro-González and Villacampa, 2016) improves the computational efficiency of algorithms from other methodologies based on geometric models of finite elements previously mentioned (Navarro-González and Villacampa, 2013; NavarroGonzález and Villacampa, 2012).

The finite element method initially generates a geometric model of finite elements, so that the model is defined by its value in the nodes of the elements (Villacampa et al., 2009). Specifically, the geometric model of finite elements is defined dividing $\Omega$ in elements, and defining in each element some points named nodes where the model is obtained. The dimension of the hypercube is defined by the number of independent or explanatory variables of the relationship to model. 
220 the number of nodes is $\mathrm{N}=(\mathrm{c}+1)^{\mathrm{n}}$. Once the geometric model in a hypercube has been defined,

221 the model is obtained by solving an optimization problem. In this way, for each mesh of finite

222 elements defined in a hypercube, a numerical model is generated.

223 In the methodology of the Galerking's formulation (Navarro-González and Villacampa, 2016),

224 defined the error function, $\mathrm{e}(\mathrm{x})$, the problem of optimization is solved by applying the method of

225 residual weights. So, using the weight functions $W_{j}$ the optimization problem is equivalent to the

226 fact that the following $\mathrm{N}$-integrals are worth zero: $\int_{\Omega} e(x) w_{j}=0, j=1,2, \ldots, N$.

227 Employing the described methodology different numerical models were generated using different

228 variables in each of them in order to select: i) the wave height that best represents the 229 characteristic points of the bars; and ii) the model that optimizes resources.

230 First, the first six models in Table 2 (M1-M6) were generated for each of the outputs (Xs, Ys, Xc,

$231 \mathrm{Yc}, \mathrm{Xe}$ and $\mathrm{Ye}$ ). Among these six models it was observed that the best results (in all outputs

232 analyzing $\mathrm{R}^{2}$, absolute error and absolute mean percentage error) were obtained with the models

233 that included as input the $H_{s, 12}$ either in deep water or in break, being slightly better the results

234 with the wave height in deep water. Thus, this variable was selected as the basis for the generation of three more models (M7-M9), in which the rest of the variables were modified to try to optimize the model. 
237 238

239

240

241

242

243

244

245

246

247

248

249

250

251

252

253

254

255

256

257

258

259

260

261

Table 2. Generated numerical models and variables used in each one. The $X$ indicates that the variable has been used in the model.

\begin{tabular}{|l|c|c|c|c|}
\hline \multirow{2}{*}{ Models } & \multicolumn{4}{|c|}{ Variables } \\
\cline { 2 - 5 } & Wave height (m) & Associated period (s) & $\mathbf{D}_{50}(\mathbf{m m})$ & Slope \\
\hline M1 & $\mathrm{H}_{\max }$ & $\mathrm{X}$ & $\mathrm{X}$ & \\
\hline M2 & $\mathrm{H}_{\mathrm{b}, \max }$ & $\mathrm{X}$ & $\mathrm{X}$ & \\
\hline M3 & $\mathrm{H}_{\mathrm{m}}$ & $\mathrm{X}$ & $\mathrm{X}$ & \\
\hline M4 & $\mathrm{H}_{\mathrm{b}, \mathrm{m}}$ & $\mathrm{X}$ & $\mathrm{X}$ & \\
\hline M5 & $\mathrm{H}_{\mathrm{s}, 12}$ & $\mathrm{X}$ & $\mathrm{X}$ & \\
\hline M6 & $\mathrm{H}_{\mathrm{b}, 12}$ & $\mathrm{X}$ & $\mathrm{X}$ & \\
\hline M7 & $\mathrm{H}_{\mathrm{s}, 12}$ & & $\mathrm{X}$ & \\
\hline M8 & $\mathrm{H}_{\mathrm{s}, 12}$ & & & $\mathrm{X}$ \\
\hline M9 & $\mathrm{H}_{\mathrm{s}, 12}$ & $\mathrm{X}$ & & $\mathrm{X}$ \\
\hline
\end{tabular}

Once the best model was determined, a validation and stability studies were performed to determine the optimal complexity (mesh density) for the model. The validation was performed using the last profile obtained in each transect, i.e. the last nine available profiles (Supplementary data 1: Distribution and use of profiles).

A perturbation of the input variables was performed to analyze the stability of the chosen model. After the analysis of the variability of the inputs by transects, it was observed that the median sediment size and period are practically constant, while the wave height presents the greatest variation with values of up to $65 \mathrm{~cm}$. For this reason, only the variable wave height is disturbed with different percentages, up to a maximum of $10 \%$. Given that the highest wave height $\left(H_{s, 12}\right)$ used in this work is $5.4 \mathrm{~m}$, applying $10 \%$ disturbance implies reaching a maximum variation of 54 $\mathrm{cm}$, very close to the maximum variation in the study area. The disturbance of the input data was randomly performed using Excel's "RANDOM" function.

\section{Results}

Table 3 shows the correlations obtained between the different inputs and outputs. For all the variables related to waves there are very low correlation values, being the higher value the one that relates the period $\left(T_{s, 12}\right)$ and $Y_{s}(r=0.128)$. The two inputs that present the greatest correlation with ouputs are: i) $D_{50}$ with a weak or very weak relationship; and ii) the slope with moderate and strong relationships.

Although the slope has a greater correlation with the study points, obtaining the sediment size in the field is simpler than obtaining the profile to define the slope. Therefore, the first generated models include the $D_{50}$, and is in the second group of generated models where the slope is included. 
Table 3. Correlations (Pearson's coefficient r) between input and output variables.

\begin{tabular}{|l|r|r|r|r|r|r|}
\hline & \multicolumn{1}{|c|}{ Xs } & \multicolumn{1}{c|}{ Ys } & \multicolumn{1}{c|}{ Xc } & \multicolumn{1}{c|}{ Yc } & \multicolumn{1}{c|}{$\mathbf{X e}$} & \multicolumn{1}{c|}{ Ye } \\
\hline $\mathrm{H}_{\max }$ & 0.092 & -0.085 & 0.069 & -0.101 & 0.013 & -0.014 \\
\hline $\mathrm{H}_{\mathrm{b}, \max }$ & 0.091 & -0.083 & 0.066 & -0.093 & 0.018 & -0.013 \\
\hline $\mathrm{T}_{\max }$ & 0.073 & -0.064 & 0.040 & -0.046 & 0.035 & -0.017 \\
\hline Direction of $\mathrm{H}_{\max }$ & 0.078 & 0.076 & 0.050 & 0.029 & 0.091 & 0.016 \\
\hline $\begin{array}{l}\text { Days between } \mathrm{H}_{\max } \text { and profile } \\
\text { survey }\end{array}$ & 0.039 & -0.004 & 0.040 & 0.011 & 0.071 & -0.011 \\
\hline $\mathrm{H}_{\mathrm{m}}$ & 0.064 & -0.057 & 0.066 & -0.088 & -0.048 & -0.001 \\
\hline $\mathrm{H}_{\mathrm{b}, \mathrm{m}}$ & 0.061 & -0.050 & 0.066 & -0.086 & -0.053 & 0.004 \\
\hline $\mathrm{T}_{\mathrm{m}}$ & 0.045 & -0.018 & 0.057 & -0.068 & -0.057 & 0.023 \\
\hline Direction of $\mathrm{H}_{\mathrm{m}}$ & 0.05 & -0.085 & 0.043 & -0.054 & 0.026 & -0.040 \\
\hline $\mathrm{H}_{\mathrm{s}, 12}$ & 0.039 & -0.011 & 0.013 & -0.043 & -0.014 & 0.033 \\
\hline $\mathrm{H}_{\mathrm{b}, \mathrm{s}, 12}$ & 0.036 & 0.020 & 0.008 & -0.030 & -0.018 & 0.048 \\
\hline $\mathrm{T}_{\mathrm{s}, 12}$ & 0.023 & 0.128 & -0.003 & 0.028 & -0.026 & 0.076 \\
\hline Direction of $\mathrm{H}_{\mathrm{s}, 12}$ & -0.005 & 0.060 & -0.007 & 0.008 & 0.012 & 0.054 \\
\hline $\mathrm{D}_{50}$ & -0.263 & -0.118 & -0.203 & 0.051 & -0.181 & -0.084 \\
\hline Slope & -0.612 & 0.406 & -0.552 & 0.407 & -0.514 & 0.337 \\
\hline
\end{tabular}

263

264 After the generation of the numerical models, it was observed that the results for the six study

265 points followed the same trend in terms of $\mathrm{R}^{2}$, absolute error and MAPE (Absolute Mean

266 Percentage Error) values. This section only shows the results for the crest (Table 4 - Table 6) it

267 is considered the most relevant factor when locating the sand bars (see the Supplementary data

268 2: Models results for the results of the start and end points of the bar). The highest $\mathrm{R}^{2}$ values are

269 obtained for models M1 and M2 (Table 4), and for models M5 and M6 which reach 0.9 and even

270 exceed it in some cases reaching 0.93 in the case of $\mathrm{Xe}$. This indicates that the inclusion of the

$271 H_{s, 12}$ in the model improves the results compared to the use of other possible wave heights such

272 as mean wave height or maximum wave height. Another important variable to include in the model

273 is the period, since if the results of the M7 and M8 models (the two models that do not include the

274 period) are compared with the rest are those that show the lowest $R^{2}$ values $(<0.7)$. Finally, it is

275 observed that using the variable slope $(\mathrm{m})$ instead of the $D_{50}$ also reduces the effectiveness of

276 the model, reaching a maximum value of 0.84 in the distance to the shoreline and 0.78 in the 277 depth. 
Table 4. $R^{2}$ for $X c$ and $Y_{c}$ in the generated numerical models from M1 to M9..

\begin{tabular}{|l|l|l|l|l|l|l|l|l|l|}
\hline Complexity & M1 & M2 & M3 & M4 & M5 & M6 & M7 & M8 & M9 \\
\hline
\end{tabular}
Distance to the shoreline $(\mathrm{X})$

\begin{tabular}{|c|c|c|c|c|c|c|c|c|c|}
\hline 40 & 0.718 & 0.684 & 0.593 & 0.566 & 0.773 & 0.759 & 0.471 & 0.553 & 0.705 \\
\hline 50 & 0.795 & 0.768 & 0.680 & 0.655 & 0.841 & 0.830 & 0.536 & 0.601 & 0.755 \\
\hline 60 & 0.839 & 0.818 & 0.748 & 0.722 & 0.883 & 0.877 & 0.582 & 0.643 & 0.794 \\
\hline 70 & 0.867 & 0.846 & 0.791 & 0.771 & 0.905 & 0.900 & 0.620 & 0.678 & 0.821 \\
\hline 80 & 0.885 & 0.866 & 0.825 & 0.804 & 0.916 & 0.913 & 0.646 & 0.709 & 0.842 \\
\hline \multicolumn{10}{|c|}{ Depth (Y) } \\
\hline 40 & 0.719 & 0.686 & 0.616 & 0.592 & 0.778 & 0.767 & 0.490 & 0.415 & 0.643 \\
\hline 50 & 0.802 & 0.775 & 0.695 & 0.672 & 0.840 & 0.830 & 0.566 & 0.475 & 0.696 \\
\hline 60 & 0.847 & 0.828 & 0.759 & 0.735 & 0.876 & 0.870 & 0.622 & 0.525 & 0.737 \\
\hline 70 & 0.875 & 0.857 & 0.797 & 0.779 & 0.895 & 0.891 & 0.662 & 0.568 & 0.763 \\
\hline 80 & 0.892 & 0.875 & 0.827 & 0.807 & 0.904 & 0.900 & 0.690 & 0.607 & 0.786 \\
\hline
\end{tabular}

279

280 Table 5 and Table 6 show the absolute error and the MAPE, respectively. The trend is the same

281 as observed for $\mathrm{R}^{2}$. Thus, in the M5 and M6 models the MAPE error committed is less than $20 \%$

282 in the distance to the shoreline and $15 \%$ in the depth. The results of both models are very similar,

283 which was to be expected if it is considered that both use the same inputs with the exception of

284 the wave height. However, since the M6 model includes the breaking wave height $\left(H_{b, s, 12}\right)-$

285 which was obtained by using Equation 1, which is a combination of the deepwater wave height

286 (the one used in M5) and the periodit could be interpreted that both models are practically the

287 same. For this reason, for the following analyses, the M5 model will be used, which uses wave

288 height in deep water $H_{s, 12}$. Both tables also show that as complexity increases, the error

289 decreases. Thus, in the case of the crest, in the M5 model the absolute error is less than $10 \mathrm{~m}$ in

290 the distance to the shoreline from a complexity of 70 , and less than $20 \mathrm{~cm}$ for a complexity of 60

291 or more.

Table 5. Absolute error in meters for $X c$ and $Y c$ in the generated numerical models from $M 1$ to

\begin{tabular}{|c|c|c|c|c|c|c|c|c|c|}
\hline \multirow{2}{*}{\multicolumn{2}{|c|}{\begin{tabular}{l|l} 
Complexity & M1 \\
Distance to the sho
\end{tabular}}} & M2 & M3 & M4 & M5 & M6 & M7 & M8 & M9 \\
\hline & & \multicolumn{8}{|c|}{ Distance to the shoreline $(X)$} \\
\hline 40 & 20.65 & 22.26 & 25.18 & 26.16 & 17.40 & 18.20 & 29.78 & 27.55 & 21.25 \\
\hline 50 & 16.79 & 18.29 & 21.80 & 22.85 & 13.79 & 14.50 & 27.44 & 25.44 & 18.31 \\
\hline 60 & 14.14 & 15.34 & 19.11 & 20.23 & 11.23 & 11.74 & 25.57 & 23.73 & 16.03 \\
\hline 70 & 12.36 & 13.44 & 16.75 & 17.90 & 9.65 & 10.04 & 23.81 & 22.19 & 14.36 \\
\hline 80 & 11.27 & 12.24 & 14.93 & 16.10 & 8.70 & 9.05 & 22.49 & 20.87 & 13.11 \\
\hline \multicolumn{10}{|l|}{ Depth (Y) } \\
\hline 40 & 0.35 & 0.37 & 0.41 & 0.43 & 0.29 & 0.30 & 0.50 & 0.53 & 0.38 \\
\hline 50 & 0.28 & 0.30 & 0.36 & 0.38 & 0.23 & 0.24 & 0.45 & 0.49 & 0.33 \\
\hline 60 & 0.23 & 0.25 & 0.31 & 0.33 & 0.19 & 0.20 & 0.42 & 0.46 & 0.30 \\
\hline 70 & 0.20 & 0.22 & 0.27 & 0.29 & 0.17 & 0.17 & 0.39 & 0.43 & 0.27 \\
\hline 80 & 0.18 & 0.20 & 0.24 & 0.26 & 0.15 & 0.16 & 0.37 & 0.40 & 0.25 \\
\hline
\end{tabular}

294 
Table 6. MAPE for $X_{c}$ and $Y_{c}$ in the generated numerical models from M1 to M9.

\begin{tabular}{|l|r|c|c|c|c|c|c|c|c|}
\hline Complexity & M1 & M2 & M3 & M4 & M5 & M6 & M7 & M8 & M9 \\
\hline Distance to the shoreline (X) \\
\hline $\mathbf{4 0}$ & $26.5 \%$ & $28.7 \%$ & $33.6 \%$ & $34.9 \%$ & $21.8 \%$ & $22.9 \%$ & $38.0 \%$ & $25.2 \%$ & $18.6 \%$ \\
\hline $\mathbf{5 0}$ & $21.1 \%$ & $23.3 \%$ & $28.9 \%$ & $30.2 \%$ & $17.1 \%$ & $18.0 \%$ & $34.9 \%$ & $23.0 \%$ & $15.7 \%$ \\
\hline $\mathbf{6 0}$ & $17.3 \%$ & $19.1 \%$ & $24.7 \%$ & $26.2 \%$ & $13.5 \%$ & $14.2 \%$ & $32.5 \%$ & $21.2 \%$ & $13.6 \%$ \\
\hline $\mathbf{7 0}$ & $14.9 \%$ & $16.5 \%$ & $21.3 \%$ & $22.7 \%$ & $11.4 \%$ & $12.0 \%$ & $30.4 \%$ & $19.8 \%$ & $12.1 \%$ \\
\hline $\mathbf{8 0}$ & $13.3 \%$ & $14.8 \%$ & $18.6 \%$ & $20.2 \%$ & $10.1 \%$ & $10.6 \%$ & $28.7 \%$ & $18.5 \%$ & $10.9 \%$ \\
\hline Depth (Y) & $18.1 \%$ & $19.4 \%$ & $22.0 \%$ & $22.9 \%$ & $14.4 \%$ & $15.0 \%$ & $26.2 \%$ & $26.0 \%$ & $16.8 \%$ \\
\hline $\mathbf{4 0}$ & $14.5 \%$ & $15.8 \%$ & $18.9 \%$ & $19.9 \%$ & $11.4 \%$ & $11.9 \%$ & $24.0 \%$ & $23.8 \%$ & $14.5 \%$ \\
\hline $\mathbf{5 0}$ & $12.0 \%$ & $13.0 \%$ & $16.0 \%$ & $17.0 \%$ & $9.4 \%$ & $9.8 \%$ & $22.3 \%$ & $22.0 \%$ & $13.0 \%$ \\
\hline $\mathbf{6 0}$ & $10.5 \%$ & $11.4 \%$ & $14.0 \%$ & $14.9 \%$ & $8.3 \%$ & $8.5 \%$ & $20.9 \%$ & $20.4 \%$ & $11.9 \%$ \\
\hline $\mathbf{7 0}$ & $9.4 \%$ & $10.3 \%$ & $12.3 \%$ & $13.2 \%$ & $7.6 \%$ & $7.9 \%$ & $19.7 \%$ & $19.0 \%$ & $11.0 \%$ \\
\hline $\mathbf{8 0}$ &
\end{tabular}

296

297 The goodness of a model must be determined by considering its fit, as well as its behaviour when predicting new data. In this sense, the generated model was validated using data from profiles that were not used in the generation of the model. For these data, the models offer very similar results to those obtained during the generation (Figure 4). For example, for the complexity of 70 the mean absolute error for the distance to the shoreline of the start point (Figure 4a) is less than $10 \mathrm{~m}$, for the crest it is less than $15 \mathrm{~m}$ and for the end point it is less than $25 \mathrm{~m}$, while at depths (Figure 4c) they are all less than $30 \mathrm{~cm}$. It should be noted that these errors decrease slightly when using the complexity of 80 , but the results between the two models are very similar.
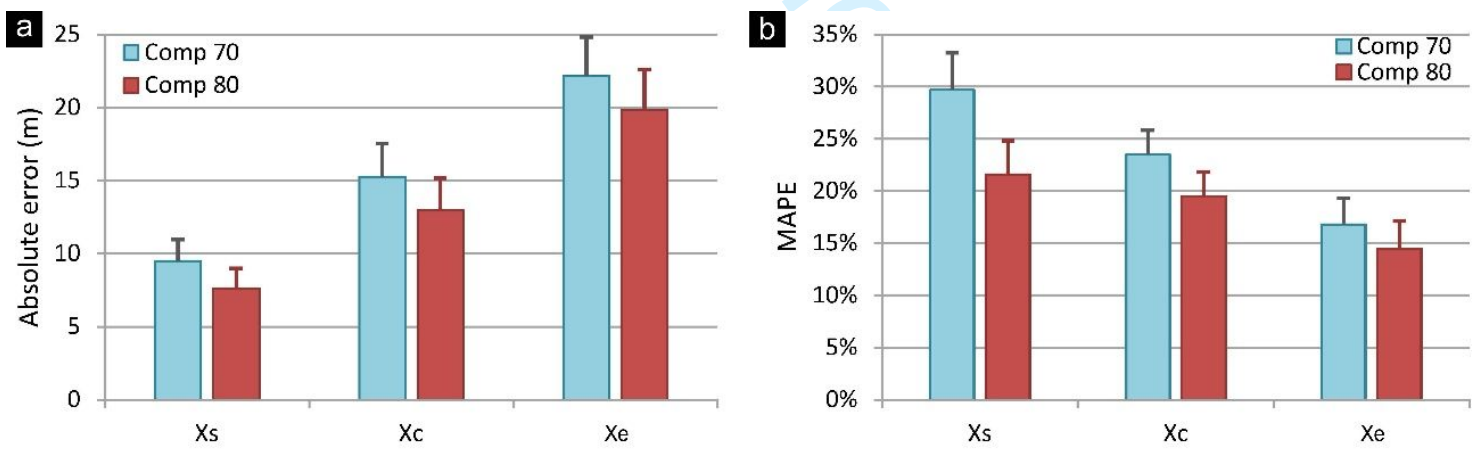

c

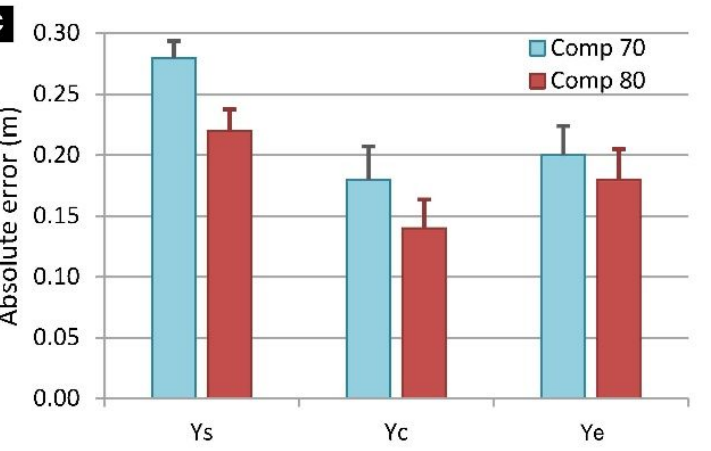

d

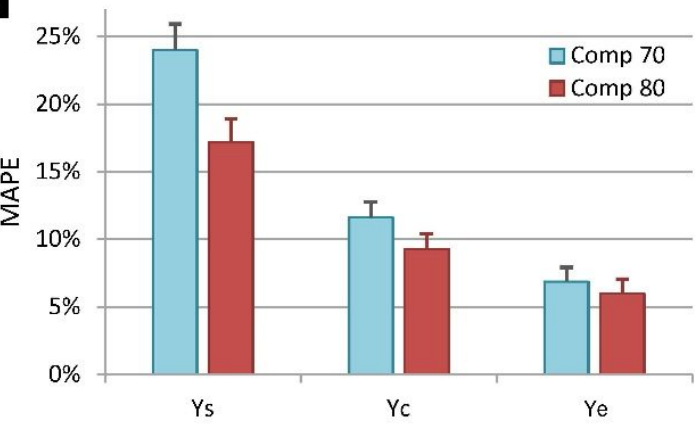

Figure 4. Results of the validations for the M5 model in the complexities of 70 and 80. 
307 To validate a model, input data can be disturbed to see how this affects the results. Figure 5 308 shows the increase in error caused by a $10 \%$ disturbance over the wave height. In the case of the model of complexity 70 the error made over the original model is around $7 \%$ in all cases except Xe where it increases to $26 \%$. However, for the 80 complexity model the errors increase by more than $15 \%$ in most cases, reaching $38 \%$ in the case of Xe. This difference between the perturbations in the 70 and 80 complexity models indicates that the 70 complexity models remain stable because the variations in the results are similar to the perturbations performed $(10 \%)$, while the 80 complexity models are relatively unstable.

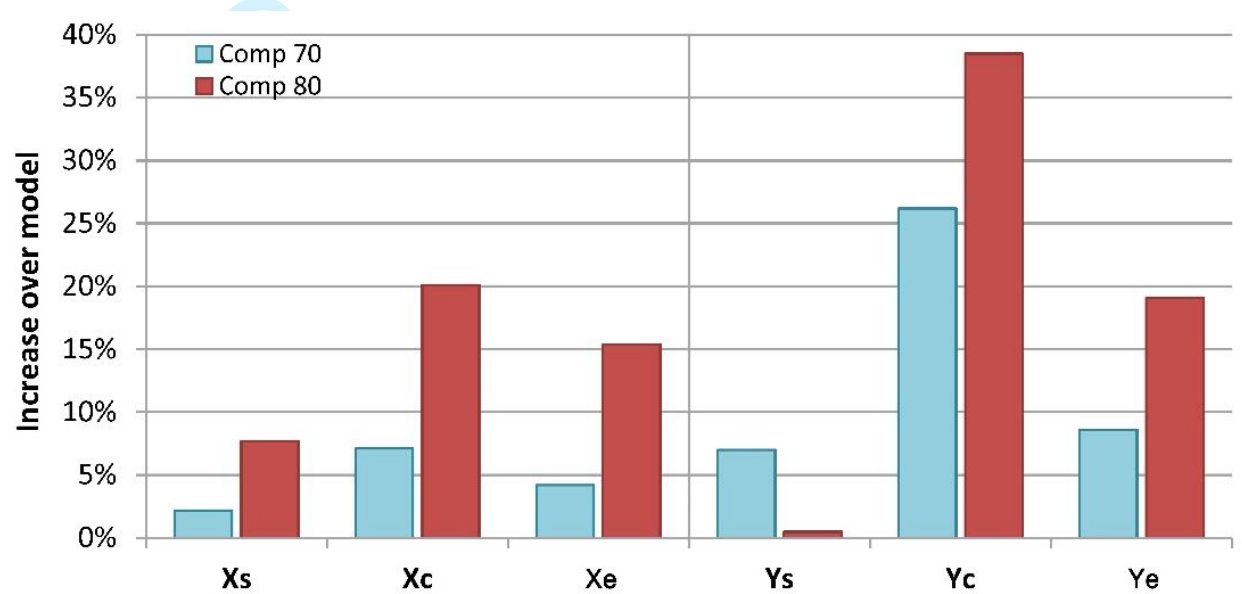

Figure 5. Increased error over the model results for wave height disturbances up to $10 \%$.

Finally, the error made in each of the profiles is compared using some of the formulations proposed by other authors and the M5 model of Comp 70 (Figure 6). In general, the average of the errors for the different authors is quite far from zero. However, there are some formulations, such as Günaydın and Kabdaşlı (2005) or Silvester and Hsu (1997), in which the average error is very close to zero, but the dispersion of the error is much greater than that committed by the M5 model. For example, for the Xc (Figure $6 b$ ) the M5 model offers maximum and minimum values of less than 100 m, while the Günaydın and Kabdaşlı (2005) model is around 200 m, and the Silvester and Hsu (1997) model has an error of between $-300 \mathrm{~m}$ and $250 \mathrm{~m}$. At depth, something similar occurs, although in most models the average errors are less than $1 \mathrm{~m}$, the dispersions are very large. On the crest, the dispersion takes the error to more than $2 \mathrm{~m}$ (Figure $6 e$ ), while at the start it reaches $4 \mathrm{~m}$ of error (Figure $6 \mathrm{~d}$ ) and at the end point to more than $8 \mathrm{~m}$ profiles. 

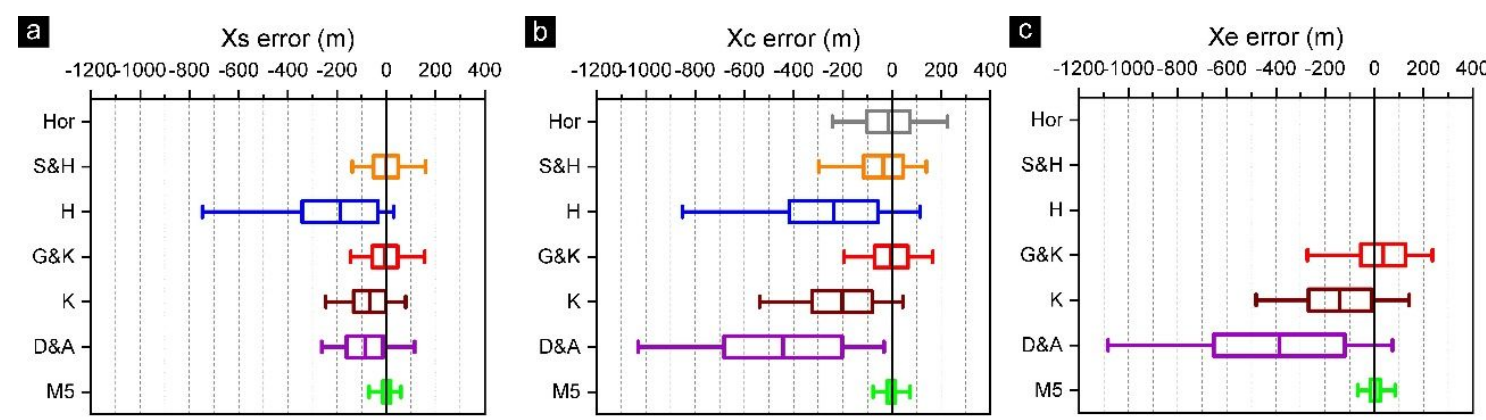

d
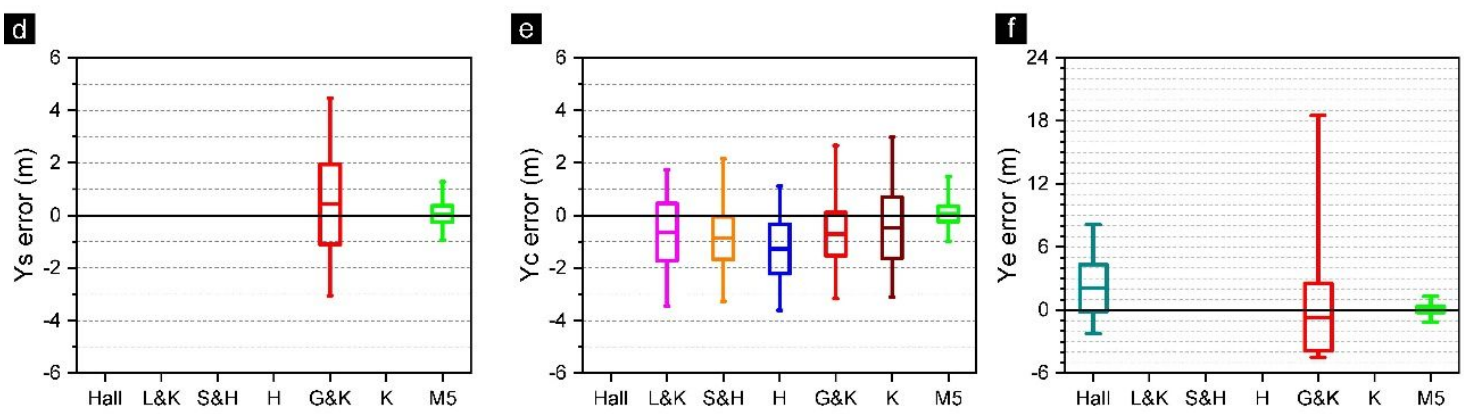

Figure 6. Comparison of the error committed (Real minus Observed) using the formulations of

other authors. Where Hor refers to Horikawa et al. (1973), Hall to Hallermeier (1978), L\&K to

Larson and Kraus (1989), S\&H to Silvester and Hsu (1997), H to Hsu (1998), G\&K to Günaydın and Kabdaşlı (2005), K to Kömürcü et al. (2007), and D\&A to Demirci and Aköz (2013).

337 The modelization of the position of sand bars has been extensively studied previously (e.g. Plant et al. (1999); Hsu et al. (2006); Smit et al. (2012); Ruessink et al. (2016)). However, a model that accurately predicts all bar positions has not been achieved. Most models successfully predict offshore movement due to heavy storms, but fail to predict onshore movement (Demirci and Aköz, 2012; Kömürcü et al., 2007; Trowbridge and Young, 1989). This work generates numerical models based on the formulation of Galerkin (Navarro-González and Villacampa, 2016) to determine the position of the start, the crest and the end of the bar in the area of the port of Valencia. The use of Galerkin's formulation of the finite element method and the corresponding improvement in computational efficiency allows analysing relationships in which a greater number of variables are involved without this implying a high time in the execution of the software.

When comparing the results obtained through the generated models and the formulations proposed by other authors, it is observed that there is a great difference in terms of the used variables and the errors committed (Table 1, Table 2 and Figure 6). In the first place, most of the 
authors deduce the variables to be used from channel tests. Moreover, most tests are performed using a fixed median sediment size and generating a straight profile with a previously established slope, which varies in the different tests, therefore the most used variable $(58.3 \%$ of the authors studied) to model the bars is the slope (Table 1). However, there are very few who conduct tests modifying the median sediment size (Demirci and Aköz, 2013; Gallagher et al., 1998; Kömürcü et al., 2007). Nevertheless, the results obtained in this work show that when the median sediment size is used, the results are much better (the error is reduced by $54 \%$ ) than when the bottom slope is used. In addition, the use of the profile slope complicates the data collection in field, since on the one hand the doubt arises up to which depth the profile has to be collected, and on the other hand, if the profile is already taken to determine the slope why not take the complete profile to determine the bar location. In this sense, it is much easier to obtain the median sediment size which, as shown in this work, is sufficient to take just once in the dry beach (provided that the beach does not undergo major sedimentological changes).

Another important variable used by all authors is wave height. Most of the tests, mentioned above, are conducted in channels, and generally under regular waves (Demirci and Aköz, 2013; Hsu, 1998; Kömürcü et al., 2007). A priori, one could think that this wave height would be similar to the mean wave height that occurs in practice, since it is the most regular. However, this research has shown that it is the maximum wave height and the $H_{s, 12}$ which produce results closest to reality (Table 4, Table 5 and Table 6). Specifically, it is the wave height $H_{s, 12}$ directly determined in deep water that offers the best results. This result agrees with Splinter et al. (2018) according to which outer bars are highly influenced by offshore waves. This may be due to the morphology of the profile and the effect of the waves on the bottom. A real profile is not straight, but has a concave shape (Dean, 1991), with which depth is achieved very quickly in the first meters of profile (from the shoreline), and then a more constant slope is reached. This fast depth reach means that the mean wave (in the study area $<1 \mathrm{~m}$ ) does not affect the bottom until it is very close to the coast (Hallermeier, 1978), and therefore is not able to produce a large movement of sediment along the profile. In that case, according to the "breakpoint" hypothesis, the bars are formed at the location of the initial wave breaking (Dally, 1987; Dean, 1973) or the existing bars move to that point (Sallenger et al., 1985; Sallenger and Howd, 1989). However, the $H_{s, 12}$ with values in the study 
379 area of between $1.50 \mathrm{~m}$ and $5.40 \mathrm{~m}$, is able to generate sediment movement along the profile, 380 and for that reason using this variable the best results are obtained.

381 When analyzing the results obtained when using the formulations proposed by other authors (Figure 6) large errors are observed, as well as a great dispersion of the data with respect to the proposed model M5. These large errors were also observed by other authors such as Demirci et al. (2015) or López et al. (2017). The possible cause of these errors is explained below. One of the formulations that makes the biggest errors is the one proposed by Demirci and Aköz (2013). This is surprising considering that this is one of the few authors that uses the same variables as the M5 model, and also includes the slope. However, if the data used are analyzed further, it can be seen that although the range of sediment sizes used by Demirci and Aköz (2013) covers the sizes found in the study area, the range of steepness used $(0.07-0.263)$ is much greater than the maximum value occurring in the study area (0.033). This could explain the large errors made when using this formulation, since according to Demirci and Aköz (2013); Demirci et al. (2015) the steepness is one of the variables that most influences the migratory movement of the bars.

Günaydın and Kabdaşlı (2005) obtain relatively good results in comparison with other authors when determining the distance to the shoreline of the different analyzed points, however the errors in the depths increase considerably. In this case the steepness does not seem to be the cause since in their tests they use values between $0.027-0.084$, so it includes the values of the study area. One of the possible causes in this case could be, as mentioned above, that these authors do not consider the median sediment size in their formulations. Another possible cause of the errors made by this formulation could be due to the fact that these authors always use the same start slope for the tests, modifying only the wave heights and periods. This could be the cause since, according to several authors, the movement of the bars is not only associated with the incident waves energy, but also with the previous morphological conditions (Pape et al., 2010; Plant et al., 1999). In other words, the initial characteristics of the beach profile, especially the depth of the water on the bar crest, play an important role in controlling the movement of the bars (Cheng and Wang, 2018). proposed by Hsu (1998). In this case, the error is not attributable to the wave steepness, as the 
408

409

410

411

412

413

414

415

416

417

418

419

420

421

422

423

424

425

426

427

428

429

430

431

432

433

434

study steepness $(0.0116-0.0619)$ covers the range of the study area's steepness. However, the median sediment size could be the cause of the error since although this variable is not taken into account in the formulation, a value of $0.15 \mathrm{~mm}$ was used for the tests, size too small compared to the usual sediment of sandy beaches. Another peculiarity of the formulation of Hsu (1998) with respect to other authors is the use of the wave incidence angle. The use of this variable may make sense, since according to some authors, the greater the obliquity of the waves, the greater the movement of the offshore bar (Cheng and Wang, 2018; Dubarbier et al., 2015; Walstra et al., 2012). However, these same authors indicate that there is no significant correlation between the incident wave angle and changes in bar height.

Therefore, to obtain the best model that determines the position of the bars in the study area: i) the independent variables that best describe the characteristics of the study area were analyzed; ii) the model generated was validated with profiles not used during generation; and iii) the stability of the model was studied by disturbing the input variables. The method followed, as well as the accuracy of the obtained model will allow positioning the defense works in an adequate way in the study area or in areas with similar conditions.

\section{Conclusions}

The morphodynamics of sand bars remains a difficult research topic due to the complex interaction between breaking waves and sediment transport in the surf zone. In this work a numerical model based on Galerkin's formulation has been developed. From the results obtained it can be stated that:

- The use of the median sediment size offers better results than the use of the profile slope.

- The wave height that best reflects the changes produced in the sand bars in practice is the wave height with a probability of $0.137 \%$ of being exceeded $\left(H_{s, 12}\right)$.

- The generated model that includes the wave height $H_{s, 12}$, its period and the median sediment size offers very good results, with mean errors lower than $15 \%$ (Xs: $23.9 \%$, Xc: $11.4 \%, \mathrm{Xe:} 8.2 \%)$ in the distances to the shoreline. And in the case of depth, the mean error is below $8 \%$ (Ys: $10.2 \%$, Yc: $8.3 \%$, Ye: $5.3 \%$ ). 
435

436

437

438

439

440

441

442

443

444

445

446

447

448

449

450

451

452

453

454

455

456

457

458

459

460

461

462

463

464

465

466

467

468

469

470

471

472

473

474

475

476

477

In summary, this research has optimized the existing models, reducing the number of inputs and

the calculation time obtaining accurate results.

\section{Acknowledgements}

This work was partially supported by the Universidad de Alicante through the project "Estudio sobre el desgaste y composición de los sedimentos y su influencia en la erosión de las playas españolas" (GRE16-09).

\section{References}

Aragonés, L.; Pagán, J.; López, I.; Navarro-González, F., and Villacampa, Y., 2019a. Galerkin's formulation of the finite elements method to obtain the depth of closure. Science of The Total Environment, 660, 1256-1263.

Aragonés, L.; Pagán, J.I.; López, M.P., and Serra, J.C., 2019b. Cross-shore sediment transport quantification on depth of closure calculation from profile surveys. Coastal Engineering, 151, 64-77.

Bagnold, R., 1966. An approach to the sediment transport problem from general physics. US Geol. Surv. Prof. Paper, 422, 231-291.

Bailard, J.A., 1982. Modeling on-offshore sediment transport in the surfzone. Coastal Engineering Proceedings, 1(18).

Brocchini, M., 2020. Wave-forced dynamics in the nearshore river mouths, and swash zones. Earth Surface Processes and Landforms, 45(1), 75-95.

Bruun, P. 1954. Coast Erosion and the Development of Beach Profiles. Vicksburg: Beach Erosion Board Technical Memorandum. U.S. Army Engineer Waterway.44.

Cheng, J. and Wang, P., 2018. Dynamic equilibrium of sandbar position and height along a low wave energy micro-tidal coast. Continental Shelf Research, 165, 120-136.

Dally, W.R., 1987. Longshore bar formation--Surf beat or undertow? Proceedings of the Coastal Sediments'87 (New York), pp. 71-86.

Dally, W.R. and Dean, R.G., 1984. Suspended Sediment Transport and Beach Profile Evolution. Journal of waterway, port, coastal, and ocean engineering, 110(1), 15-33.

Dean, R.G., 1973. Heuristic models of sand transport in the surf zone. Proceedings of the Conference on Engineering Dynamics in tle Surf Zone, Sydney, Australia, 208-214.

Dean, R.G. 1977. Equilibrium Beach Profiles: U.S. Atlantic and Gulf Coasts. Department of Civil Engineering. Ocean Engineering Technical Report. Newark, Delaware.: University of Delaware.12, 1-44.

Dean, R.G., 1991. Equilibrium beach profiles - Characteristics and applications. Journal of Coastal Research, 7(1), 53-84.

Demirci, M. and Aköz, M.S., 2012. An investigation on the formation of submerged bar under surges in sandy coastal region. China Ocean Engineering, 26(3), 535-546.

Demirci, M. and Aköz, M.S., 2013. Investigation of bar parameters occurred by cross-shore sediment transport. International Journal of Naval Architecture and Ocean Engineering, 5(2), 277-286.

Demirci, M.; Üneş, F., and Aköz, M.S., 2015. Prediction of cross-shore sandbar volumes using neural network approach. Journal of Marine Science and Technology, 20(1), 171-179.

Dubarbier, B.; Castelle, B.; Marieu, V., and Ruessink, G., 2015. Process-based modeling of crossshore sandbar behavior. Coastal Engineering, 95, 35-50. 
Ecolevante 2006. Estudio ecocartográfico del litoral de las provincias de Alicante y Valencia, Dirección General de Costas, Ministerio de Medio Ambiente, Spain, [Available online: http://www.mapama.gob.es/es/costas/temas/proteccioncosta/ecocartografias/ecocartografia-alicante.aspx]. pp.

Elgar, S., 1987. Relationships involving third moments and bispectra of a harmonic process. Acoustics, Speech and Signal Processing, IEEE Transactions on, 35(12), 1725-1726.

Elgar, S.; Gallagher, E.L., and Guza, R.T., 2001. Nearshore sandbar migration. Journal of Geophysical Research: Oceans, 106(C6), 11623-11627.

Falchetti, S.; Conley, D.C.; Brocchini, M., and Elgar, S., 2010. Nearshore bar migration and sediment-induced buoyancy effects. Continental Shelf Research, 30(2), 226-238.

Gallagher, E.L.; Elgar, S., and Guza, R., 1998. Observations of sand bar evolution on a natural beach. Journal of geophysical research, 103, 3203-3215.

Günaydın, K. and Kabdaşlı, M.S., 2005. Investigation of Offshore Bar Geometry Under Regular and Irregular Waves. Journal of Coastal Research, 374-382.

Hallermeier, R.J., 1978. Uses for a calculated limit depth to beach erosion. Proceedings of the Proceedings of the 16th Coastal Engineering Conference (Hamburg, Germany), pp. 14931512.

Henderson, S.M.; Allen, J.S., and Newberger, P., 2004. Nearshore sandbar migration predicted by an eddy-diffusive boundary layer model. Journal of Geophysical Research: Oceans (1978-2012), 109(C6).

Hoefel, F. and Elgar, S., 2003. Wave-induced sediment transport and sandbar migration. Science, 299(5614), 1885-1887.

Holman, R.A. and Sallenger, A.H., Jr., 1993. Sand Bar Generation: A Discussion of the Duck Experiment Series. Journal of Coastal Research, 76-92.

Horikawa, K.; Sunamura, T., and Koit, H., 1973. A study on beach transformation due to waves. Proceedings of the 20th Conference on Coastal Engineering in Japan, 357-363.

Hsu, T.-J.; Elgar, S., and Guza, R.T., 2006. Wave-induced sediment transport and onshore sandbar migration. Coastal Engineering, 53(10), 817-824.

Hsu, T.-W., 1998. Geometric characteristics of storm-beach profiles caused by inclined waves. Ocean Engineering, 25(1), 69-84.

Ihcantabria 2013. Análisis Matemático y Estadístico de Variables Medioambientales (AMEVA). In: CANTABRIA, U.D. (ed.). Cantabria, Spain. Available online: http://ihameva.ihcantabria.com/.

Komar, P.D. and Gaughan, M.K., 1972. Airy wave theory and breaker height prediction. Proceedings of the 13th Conference on Coastal Engineering (Vancouver, Canada), pp. 405-418.

Kömürcü, M.i..; Özölçer, ì.H.; Yüksek, Ö., and Karasu, S., 2007. Determination of bar parameters caused by cross-shore sediment movement. Ocean Engineering, 34(5-6), 685-695.

Kraus, N.C. and Larson, M., 1988. Prediction of initial profile adjustment of nourished beaches to wave action. Proceedings of the Proceedings of 1988 National Conference on Beach Preservation Technology, pp. 125-137.

Kriebel, D.L. and Dean, R.G., 1985. Numerical simulation of time-dependent beach and dune erosion. Coastal Engineering, 9(3), 221-245.

Larson, M. and Kraus, N.C. 1989. SBEACH: numerical model for simulating storm-induced beach change. Report 1. Empirical foundation and model development. DTIC Document.

Lippmann, T. and Holman, R., 1990. The spatial and temporal variability of sand bar morphology. Journal of Geophysical Research: Oceans (1978-2012), 95(C7), 11575-11590.

López, I.; Aragonés, L.; Villacampa, Y., and Serra, J.C., 2017. Neural network for determining the characteristic points of the bars. Ocean Engineering, 136, 141-151.

Navarro-González, F.J. and Villacampa, Y., 2012. A new methodology for complex systems using n-dimensional finite elements. Advances in Engineering Software., 48(1), 52-57. 
Navarro-González, F.J. and Villacampa, Y., 2013. Generation of representation models for complex systems using Lagrangian functions. Advances in Engineering Software, 64, 3337.

Navarro-González, F.J. and Villacampa, Y., 2016. A finite element numerical algorithm for modelling and data fitting in complex systems. International Journal of Computational Methods and Experimental Measurements, 4(1), 100-113.

Pagán, J.I.; Villacampa, Y.; Aragonés, L., and López, I., 2017. A Software Application To Obtain The Depth Of Closure From Beach Profile Data. International Journal of Computational Methods and Experimental Measurements, 5, 750-759.

Pape, L.; Kuriyama, Y., and Ruessink, B., 2010. Models and scales for cross-shore sandbar migration. Journal of Geophysical Research: Earth Surface (2003-2012), 115(F3).

Pape, L.; Ruessink, B.G.; Wiering, M.A., and Turner, I.L., 2007. Recurrent neural network modeling of nearshore sandbar behavior. Neural Networks, 20(4), 509-518.

Plant, N.; Holman, R.; Freilich, M., and Birkemeier, W., 1999. A simple model for interannual sandbar behavior. Journal of Geophysical Research: Oceans (1978-2012), 104(C7), $15755-15776$.

Różyński, G., 2003. Data-driven modeling of multiple longshore bars and their interactions. Coastal Engineering, 48(3), 151-170.

Ruessink, B.G.; Blenkinsopp, C.; Brinkkemper, J.A.; Castelle, B.; Dubarbier, B.; Grasso, F.; Puleo, J.A., and Lanckriet, T., 2016. Sandbar and beach-face evolution on a prototype coarse sandy barrier. Coastal Engineering, 113, 19-32.

Sallenger, A.H.; Holman, R.A., and Birkemeier, W.A., 1985. Storm-induced response of a nearshore-bar system. Marine Geology, 64(3-4), 237-257.

Sallenger, A.H. and Howd, P.A., 1989. Nearshore bars and the break-point hypothesis. Coastal Engineering, 12(4), 301-313.

Serra Peris, J. and Medina, J.R., 1996. Beach monitoring program of Valencia (Spain). Coastal Engineering, 590-591.

Silvester, R. and Hsu, J.R., 1997. Coastal stabilization. Advanced Series on Ocean Engineering, 14. Smit, M.W.J.; Reniers, A.J.H.M., and Stive, M.J.F., 2012. Role of morphological variability in the evolution of nearshore sandbars. Coastal Engineering, 69, 19-28.

Splinter, K.D.; Gonzalez, M.V.G.; Oltman-Shay, J.; Rutten, J., and Holman, R., 2018. Observations and modelling of shoreline and multiple sandbar behaviour on a high-energy meso-tidal beach. Continental Shelf Research, 159, 33-45.

Thornton, E.B.; Humiston, R.T., and Birkemeier, W., 1996. Bar/trough generation on a natural beach. Journal of Geophysical Research: Oceans, 101(C5), 12097-12110.

Trowbridge, J. and Young, D., 1989. Sand transport by unbroken water waves under sheet flow conditions. Journal of Geophysical Research: Oceans (1978-2012), 94(C8), 10971-10991.

Villacampa, Y.; Navarro-González, F.J., and Llorens, J., 2009. A geometric model for the generation of models defined in Complex Systems. Ecosystems and Sustainable Development VII, 71-82.

Walstra, D.J.R.; Reniers, A.J.H.M.; Ranasinghe, R.; Roelvink, J.A., and Ruessink, B.G., 2012. On bar growth and decay during interannual net offshore migration. Coastal Engineering, 60, 190-200.

Winant, C.D.; Inman, D.L., and Nordstrom, C.E., 1975. Description of seasonal beach changes using empirical eigenfunctions. Journal of geophysical research, 80(15), 1979-1986. 